\title{
ACOLHIMENTO À PESSOA COM DOENÇA FALCIFORME NA URGÊNCIA E EMERGÊNCIA EM SALVADOR- BAHIA
}

\author{
Letícia Santos de Carvalho ${ }^{1}$; Evanilda Santana de Souza Carvalho²; Aline Gomes Silva \\ Xavier $^{3}$ e Kayque Neves da Silva ${ }^{4}$ \\ 1. Bolsista PIBIC/CNPq, Graduanda em Medicina, Universidade Estadual de Feira de Santana, e-mail: \\ leticiacarvalho.fsa@hotmail.com \\ 2. Orientadora, Departamento de Saúde, Universidade Estadual de Feira de Santana, e-mail: evasscarvalho@yahoo.com.br \\ 3. Doutoranda do Programa de Pós- Graduação em Saúde Coletiva (PPGSC- UEFS), bolsista FAPESB, participante do \\ Núcleo Interdisciplinar sobre Desigualdades em Saúde (NUDES), Departamento de Saúde, Universidade Estadual de Feira \\ de Santana, e-mail: asgx80@gmail.com \\ 4. Participante do Núcleo Interdisciplinar sobre Desigualdades em Saúde (NUDES), Departamento de Saúde, Universidade \\ Estadual de Feira de Santana, e-mail: kayque_sn@hotmail.com
}

PALAVRAS-CHAVE: acolhimento, serviço hospitalar de emergência, anemia falciforme.

\section{INTRODUÇÃO}

Emergência é a circunstância de agravo à saúde que exige intervenção médica imediata por haver risco iminente de vida, enquanto a urgência é uma classificação atribuída aos casos em que há risco à vida, mas com a necessidade de suporte à saúde de caráter menos imediatista (ZANELATTO; DAL PAI, 2010). Tornar a passagem pelo serviço hospitalar de emergência mais amena e humanizada é um desafio facilitado com as práticas de acolhimento. Acolher ultrapassa a perspectiva de acesso ao serviço de saúde; é mais que uma ação de porta de entrada e recepção do usuário. É um processo contínuo que envolve sensibilidade e conhecimento técnico-científico dos profissionais para identificar necessidades de saúde derivadas de processos sociais, físico-biológicos, mentais e ambientais. É a responsabilização interessada e ativa pela condição de saúde do usuário que resulta em adequação do serviço de saúde ao perfil da população atendida (GUEDES; HENRIQUES; LIMA, 2013).

Nessa seara da busca por atendimento em SHE se enquadram as pessoas com doença falciforme, patologia crônica que compromete o desenvolvimento normal da hemácia e repercute com complicações como crises álgicas secundárias a vaso-oclusão, priaprismo, sequestro esplênico, infecções (BRASIL, 2009). Assim, buscando ampliar o conhecimento acerca da experiência de pessoas com DF em busca de cuidados este estudo apresenta como objeto o acolhimento a pessoas com DF nos serviços de urgência e emergência em Salvador (Bahia) e a questão norteadora é: como pessoas com DF percebem o acolhimento nos serviços de urgência e emergência no município de Salvador?

A fim de respondê-la, definiram-se os seguintes objetivos divididos em geral e específicos: compreender a percepção dos sujeitos com DF a respeito do acolhimento na urgência e emergência; identificar qual/quais o/os conceito de acolhimento a população estudada internaliza; apontar criticamente pontos positivos e negativos do acolhimento ao doente falciforme na urgência e emergência em Salvador-BA; analisar causas que conduzem pessoas com DF a buscar atendimento em serviços de urgência e emergência.

Esse estudo se justifica pela possibilidade de adentrar no imaginário dos usuários da rede de serviços e assim compreender seus anseios, o que identificam como limitações no acolhimento e consequentemente possibilitar uma devolutiva dos resultados para os 
profissionais de saúde e de gestão. A identificação de lacunas na compreensão do acolhimento e das causas que devem levá-lo ao serviço terciário ou ao primário, a explicitação de pontos positivos e negativos do atendimento podem auxiliar os profissionais e acadêmicos no planejamento de mudanças e atitudes de enfrentamento.

\section{MATERIAL E MÉTODOS OU METODOLOGIA (ou equivalente)}

Estudo desenvolvido a partir de abordagem qualitativa. Participaram dez indivíduos, maiores, que possuem DF, já utilizaram serviço de urgência e emergência e frequentavam as reuniões mensais da Associação Baiana de Pessoas com Doença Falciforme (ABADFAL). Para a produção de dados empíricos foram empregadas entrevistas semiestruturadas. A análise dos dados empíricos foi realizada por meio de análise de conteúdo proposta por Bardin (2011).

O presente estudo está vinculado ao projeto de pesquisa "Representações sobre o corpo e a doença falciforme: repercussões sobre a vida cotidiana, o cuidado e a sexualidade", encaminhado ao Comitê de Ética em Pesquisa (CEP) da UEFS sob o parecer de número 5269/2013, além disso seguiram-se as normas regulamentadoras da Resolução 466/2012 do Conselho Nacional de Saúde.

\section{RESULTADOS E/OU DISCUSSÃO (ou Análise e discussão dos resultados)}

Foram entrevistados quatro homens e seis mulheres. Todos referiram-se como negros (pretos ou pardos), encontravam-se entre a segunda e a quinta década de vida. Quanto ao estado civil, três estavam casados, um em união estável e seis, solteiros, isso pode se associar a fatores de isolamento social e exclusão social de pessoas com DF. A renda dos participantes variou de nenhum a quatro salários mínimos e um indivíduo não quis referir. Dos entrevistados, nove possuíam anemia falciforme e um apresentava o genótipo HbSC. Complicações que já conduziram indivíduos aos serviços de urgência e emergência foram em unanimidade crise álgica, em segundo lugar de frequência houve as infecções e como outras complicações também encontradas encontrou-se acidente vascular encefálico, colecistopatia calculosa e síndrome torácica aguda.

Categoria 01: Definição de acolhimento: O que acolher significa para mim?

Houve uma miríade de concepções acerca da definição de acolhimento, uma delas foi a visão do ser humano integralmente, desfocando da patologia e isso envolve alguns aspetos citados por Pelisoli e colaboradores (2014) o acolhimento humanizado pressupõe a escuta sensível com intuito de aproximação e vinculação, observando o significado multidimensional da experiência vivenciada pelo usuário.

Acho que a preocupação com o outro, não o enfoque na doença, apesar de a pessoa estar doente ali é um ser humano, é a pessoa e não a dor. Aquela coisa automática de querer resolver os sintomas, não é assim, é sentar, explicar, conversar, saber, envolver (...) é como o outro o vê, ele o entender mesmo que não esteja sentindo a sua dor e você ficar à vontade e seguro de que será atendido e medicado. F04

Outros entrevistados destacavam a importância da equipe multidisciplinar e sinalizavam que o acolhimento envolve todos os trabalhadores do serviço, não apenas os profissionais de saúde. As pessoas com DF, no presente estudo, alertam que para acolher se requer que haja infraestrutura e para isso um dos elementos necessários é a articulação da rede 
para evitar a peregrinação que aumenta os riscos de piora das complicações que os conduziram aos serviços. Entretanto, Azevedo e colaboradores (2010) constataram carências nesse campo, visto que a desarticulação dos diferentes níveis de atenção do sistema de saúde confirma o conhecimento empírico da realidade, retratada historicamente pela supervalorização do enfoque curativo e hospitalocêntrico.

CATEGORIA 02: Fatores limitantes para o adequado acolhimento em Salvador- BA

Aspectos negativos do acolhimento o limitam. A grande demanda de pacientes atendidos, a imprevisibilidade desses atendimentos, o espaço físico reduzido, a falta de priorização do atendimento, entre outros fatores, fazem da emergência um local com extrema dificuldade de organização do trabalho (SHIROMA E PIRES, 2011).

Ainda falta muito preparo, principalmente na emergência, você só é mais bem atendida pela equipe de hematologia, mas ainda tem muito que preparar essa sensibilidade e ver logo a medicação que possa amenizar a dor do paciente e dar valor a todos os sintomas que o paciente está dizendo. Muitas vezes já senti que o que eu estava dizendo não foi valorizado. F05

Além disso, estudo comparativo de Lazio e colaboradores (2010) investigou o manejo de analgésicos nos serviços de emergência em pessoas com crise álgica DF e cólica renal e evidenciou atraso no manejo e tratamento inadequado em pessoas com DF embora elas apresentassem mesmo estado de gravidade ou superior à admissão. Isso se relaciona coma invisibilidade acerca da DF e o estigma e racismo que afetam os sujeitos adoecidos.

CATEGORIA 03: Aspectos positivos do acolhimento em Salvador- BA e novas perspectivas

Aspectos positivos no acolhimento são considerados incomuns, visto que raramente acontecem segundo os entrevistados. Nesse sentido, faz-se necessário intervir para que os fatores limitantes sejam reduzidos. Um deles é o racismo que gera disparidades sociais no atendimento de saúde, muitas pessoas com DF e seus familiares afirmam que a cor importa na prestação do cuidado de saúde e ser negro afeta negativamente tal cuidado (NELSON E HACKMAN, 2013).

Além do racismo, há o desconhecimento sobre a DF que pode ser amenizado com programas de educação permanente e divulgação na mídia. Por fim, visto que a escuta sensível é elemento considerado para classificar o acolhimento, o uso eficiente de estratégias de comunicação e informação em saúde no âmbito das unidades de emergência do SUS pode influenciar significativamente na impressão dos usuários em relação ao serviço prestado (SILVA et al, 2016).

\section{CONSIDERAÇÕES FINAIS}

O presente estudo teve como objetivos geral e específicos compreender a percepção dos sujeitos com DF a respeito do acolhimento na urgência e emergência; identificar qual/quais o/os conceito de acolhimento a população estudada internaliza; apontar criticamente pontos positivos e negativos do acolhimento ao doente falciforme na urgência e emergência em Salvador-BA; analisar causas que conduzem pessoas com DF a buscar atendimento em serviços de urgência e emergência e revelou que o acolhimento em Salvador- BA é ainda incipiente e muito limitado, pode-se afirmar que é quase inexistente nesse município. A definição de acolhimento variou de porta de entrada, momento que precede os cuidados de saúde, até processo que envolve todas as etapas da estada no serviço de urgência e emergência. Ainda nesse sentido, instâncias que inspiram o progresso no acolhimento são o Centro de Referência em Hemoglobinopatias e a ABADFAL, visto que são considerados espaços de exercício do controle social e de primor no cuidado a este grupo. 
Entre os pontos negativos na realidade das emergências estão o tempo de atendimento, a estrutura física do espaço, a má comunicação entre equipe e sujeito adoecido, desvalorização da dor e das vivências dos sujeitos adoecidos, falta de informação sobre DF. Nesse contexto marcado predominantemente por experiências negativas, as positivas são vistas como esporádicas. Há, portanto, necessidade de qualificação de profissionais da rede de urgência e emergência para a compreensão da DF, capacitação das pessoas adoecidas para identificarem qual porta devem acessar em cada necessidade de busca ao sistema de saúde e de reestruturação dos espaços de cuidado sanando os problemas de infraestrutura destacados entre os entrevistados.

Apresenta-se como limitação do estudo o momento utilizado para realizar as entrevistas (antes ou após a reuniões da ABADFAL) que pode ter apressado os entrevistados a finalizar a entrevista e um possível viés de seleção o fato de participantes desse grupo terem acesso a mais discussões sobre temáticas de saúde e estarem mais engajados na causa social de luta pelos seus direitos. Nesse sentido, sugere-se que estudos posteriores sejam realizados com mais pessoas com DF e que não participem da ABADFAL.

\section{REFERÊNCIAS}

ZANELATTO, Maggi Zanelatto; DAL PAI, Daiane. Práticas de acolhimento no serviço de emergência: a perspectiva dos profissionais de enfermagem. Cienc Cuid Saud, Paraná, v. 9, n. 2, p. 358-365, 2010.

GUEDES, Maria Vilani Cavalcante; HENRIQUES, Ana Ciléia Pinto Teixeira; LIMA, Morgama Mara Nogueira. Acolhimento em um serviço de emergência: percepção dos usuários. Rev. bras. enferm., Brasília , v. 66, n. 1, p. 31-37, Feb. 2013 . Available from $<$ http://www.scielo.br/scielo.php?script=sci_arttext\&pid=S0034-

$71672013000100005 \& \operatorname{lng}=\mathrm{en} \& \mathrm{nrm}=\mathrm{iso}>$. access on 27 Mar. 2016. http://dx.doi.org/10.1590/S0034-71672013000100005.

BRASIL. Ministério da Saúde. Secretaria de Atenção à Saúde. Departamento de Atenção Especializada. Manual de eventos agudos em doença falciforme- Brasília: Editora do Ministério da Saúde, 2009. ISBN 978-85-334-1621-5.

BARDIN, L. Análise de conteúdo. São Paulo: Edições 70. 2011.

PELISOLI et al. Acolhimento em saúde: uma revisão sistemática em periódicos brasileiros.

Estudos de Psicologia, Campinas. v. 31, n. 2. P. 225-235, Abril- Junho, 2014.

AZEVEDO, Ana Lídia de Castro Sajioro, et al. Organização de serviços de emergência hospitalar: uma revisão integrativa de pesquisas. Rev. Eletr. Enf. [Internet]. v. 12, n. 4, p. 736-745. Out/ Dez 2010. Available from: http://dx.doi.org/10.5216/ree.v12i4.6585. SHIROMA, Lícia M. B.; PIRES, Denise E. P.. Classificação de risco em emergência - um desafio para as/os enfermeiras/os. Enfermagem em Foco. v. 2, n. 1, p. 14-17. 2011. Nelson SC; Hackman HW. Race matters: perceptions of race and racism in a sickle cell center. Pediatr Blood Cancer;60(3):451-4, 2013 Mar.

SILVA, Pollyane Liliane et al . Acolhimento com classificação de risco do serviço de ProntoSocorro Adulto: satisfação do usuário. Rev. esc. enferm. USP, São Paulo, v. 50, n. 3, p. 427-433, June 2016. Available from <http://www.scielo.br/scielo.php?script=sci_arttext\&pid=S008062342016000300427\&lng=en\&nrm=iso>. access on 02 Dec. 2016. http://dx.doi.org/10.1590/S0080-623420160000400008. 